\title{
EFICIÊNCIA DOS TESTES DE VIGOR NA AVALIAÇÃO DA QUALIDADE FISIOLÓGICA DE SEMENTES DE MULUNGU (Erythrina velutina WILLD. ${ }^{1}$
}

\author{
SÍLVIA REGINA SILVA DE OLIVEIRA BENTO², ANA ELISA OLIVEIRA DOS SANTOS²; \\ DALILA REGINA MOTA DE MELO ${ }^{3}$, SALVADOR BARROS TORRES ${ }^{4}$
}

\begin{abstract}
RESUMO - O trabalho foi realizado para verificar a eficiência de testes de vigor na avaliação da qualidade fisiológica de sementes de mulungu. Em dois lotes de sementes, determinaram-se o teor de água, peso de mil sementes, peso hectolítrico, comprimento, largura e espessura de sementes, germinação, primeira contagem de germinação, emergência de plântulas em campo, índice de velocidade de emergência, teor de água após o envelhecimento, envelhecimento acelerado, teste de tetrazólio, altura, diâmetro do colo, massa de matéria verde e seca de plântulas. As médias de cada caráter avaliado nos dois lotes foram comparadas utilizando-se intervalos de confiança obtidos pelo teste t com $95 \%$ de probabilidade. Os resultados dos testes de germinação, primeira contagem de germinação, índice de velocidade de emergência e envelhecimento acelerado foram coerentes com os de emergência de plântulas, realizado em condições de viveiro. Com exceção do teste de tetrazólio, os demais testes indicaram homogeneidade entre os lotes de sementes de mulungu, o que foi confirmado pelas análises dos caracteres morfológicos das sementes, há, contudo, necessidade de estudos mais detalhados sobre a aplicabilidade do teste de tetrazólio para a espécie.
\end{abstract}

Termos para indexação: Fabaceae, germinação, sementes florestais, plântulas.

\author{
EFFICIENCY OF VIGOR TESTS TO EVALUATE PHYSIOLOGICAL QUALITY \\ OF Erythrina velutina Willd. SEEDS
}

\begin{abstract}
The objective of this study was to evaluate the efficiency of vigor tests for Erythrina velutina Willd (mulungu) seeds. Two seed lots were evaluated for seed moisture content, 1000 seeds weight, hectoliter weight, seed length, width and thickness, germination, first germination count, field seedling emergence, seedling emergence speed, moisture content after accelerated ageing, accelerated ageing, tetrazolium test, seedling height, root collar diameter, seedling fresh and dry weights. The means were compared using the t test with $95 \%$ confidence intervals. The results for germination, first germination count, speed of seedling emergence and accelerated ageing tests coincided with seedling emergence test results in the greenhouse. All tests indicated lot homogeneity, except for the tetrazolium test, and this was confirmed by seeds morphological traits analysis. Further studies are needed to determine tetrazolium test applicability in E. velutina seeds.
\end{abstract}

Index terms: Fabaceae, germination, forest seeds, seedling.

${ }^{1}$ Submetido em. 21/07/2009. Aceito para publicação em 31/05/2010.

${ }^{2}$ Eng. Agr. Doutoranda em Fitotecnia, Dep. de Ciências Vegetais/ UFERSA-RN, Caixa Postal 137, CEP 59.625-900. Mossoró, RN; e-mail: silviaoliveira@hotmail.com; aeods@ig.com.br.

\footnotetext{
${ }^{3}$ Lic. em Ciência Agrárias, Mestranda em Fitotecnia, Depto de Ciências Vegetais/UFERSA-RN, CP. 137, CEP: 37, CEP: 59625-900, MossoróRN. e-mail: dalilaregina@hotmail.com

${ }^{4}$ Eng. Agr., Dr., Pesquisador da EMPARN/UFERSA, CP. 137, CEP: 59625-900, Mossoró-RN, e-mail: sbtorres@ufersa.edu.br
} 


\section{INTRODUÇÃO}

As possibilidades de esgotamento do potencial madeireiro existente estão ligadas à erosão genética e as poucas informações sobre produção de sementes e mudas das espécies nativas (Barbosa et al., 2004). Apesar do aumento considerável dos estudos com sementes de espécies florestais brasileiras, os tecnologistas de sementes florestais encontram ainda dificuldades no estabelecimento de técnicas de produção e avaliação da qualidade das sementes, devido à grande variação biomorfológica nos frutos e sementes das diferentes espécies (Gonçalves et al., 2009; Martins et al., 2009).

O mulungu (Erythrina velutina Willd.) é uma Fabaceae de porte arbóreo, atingindo alturas de $8 \mathrm{~m}$ a $12 \mathrm{~m}$, com características de planta decídua e heliófila (Lorenzi, 2002). Sua ocorrência estende-se desde o Estado do Ceará até o de São Paulo, sendo muito comum em várzeas úmidas e margens de rios da Caatinga (Silva Júnior, 2005). Caracteriza-se por sua rusticidade e resistência à seca e, devido à sua capacidade de fixar nitrogênio, é muito utilizada na recuperação de áreas degradadas (Melo e Cunha, 2008; Nunes et al., 2008; Matheus e Lopes, 2009).

Devido à ênfase na propagação de espécies florestais e sendo a semente o principal meio para a reprodução dessas espécies, ressalta-se a necessidade de gerar conhecimento para a análise das mesmas. Para avaliar a qualidade fisiológica das sementes usam-se testes de germinação e vigor, caracterizando-se seus atributos físicos e fisiológicos uma vez que, nas espécies nativas, a variação na germinação é muito grande entre diferentes populações (Silva e Carvalho, 2008).

Entre os testes de vigor disponíveis encontram-se aqueles relacionados ao teste de germinação, como o da primeira contagem de germinação, que determina o vigor relativo dos lotes e os de desenvolvimento de plântulas (Nakagawa, 1999). Dentre os demais testes de vigor, os testes de envelhecimento acelerado e o de tetrazólio, têm proporcionado resultados promissores na avaliação da qualidade de sementes de espécies arbóreas. $\mathrm{O}$ teste de envelhecimento acelerado tem como princípio o aumento na taxa de deterioração das sementes por meio de sua exposição às altas temperaturas $\left(40 \mathrm{a} 45^{\circ} \mathrm{C}\right)$ e umidade relativa do ar $(100 \%)$, considerados fatores ambientais preponderantes na intensidade e velocidade de deterioração (Tekrony, 1995; Marcos Filho, 1999). Assim, sementes de baixa qualidade deterioram-se mais rapidamente, apresentando queda diferenciada da viabilidade (Paiva et al., 2008).

A avaliação da viabilidade das sementes por meio de testes rápidos como o de tetrazólio, agiliza as decisões quanto ao manejo de lotes de sementes durante as etapas de pré e de pós-colheita (Pinto et al., 2009). Esse teste permite determinar a presença, localização e natureza das alterações nos tecidos das sementes por meio da coloração (França Neto et al., 1999). A eficiência do teste de tetrazólio para avaliar a viabilidade das sementes, depende do desenvolvimento e do uso de método adaptado para cada espécie, como a definição de condições apropriadas para o pré-condicionamento, o preparo, a coloração e a avaliação das sementes (Pinto et al., 2009).

Apesar da grande utilidade dos testes de vigor, um único teste de vigor não é capaz de caracterizar todas as interações possíveis entre as sementes e as condições ambientais antes, durante e após a colheita, bem com as verificadas por ocasião da semeadura. Nesse sentido, recomenda-se o uso de mais de um teste de vigor para aumentar as informações e diminuir os erros associados à decisão de se aceitar ou rejeitar um lote de sementes para armazenamento ou semeadura (Mendonça et al., 2008). De acordo com as especificações da AOSA (1983), amostras de sementes que originam plântulas com maior comprimento da parte aérea e massa de matéria verde ou seca, num mesmo período de tempo, são consideradas mais vigorosas, sendo estes parâmetros também utilizados como testes de vigor.

Considerando-se a importância do mulungu como espécie medicinal, ornamental e madeireira e tendo em vista que os testes de vigor fornecem informações mais precisas do potencial fisiológico, sendo excelentes ferramentas para avaliar a qualidade de sementes de diversas espécies, esse trabalho teve como objetivo avaliar a eficiência de testes de vigor em sementes dessa espécie.

\section{MATERIAL E MÉTODOS}

O trabalho foi conduzido no Laboratório de Análises de Sementes (LAS) do Departamento de Ciências Vegetais e em casa de vegetação da Universidade Federal Rural do Semi-Árido (UFERSA), em Mossoró, RN, em maio de 2009. Foram utilizados dois lotes de sementes de mulungu provenientes de dois municípios da região do semiárido do estado do Rio Grande do Norte, distantes aproximadamente $100 \mathrm{~km}$ entre si. As sementes do lote 1 foram coletadas no mês de novembro de 2007, em Carnaúba dos Dantas, situada a $306 \mathrm{~m}$ de altitude $\left(06^{\circ} 33^{\prime} 20^{\prime \prime} \mathrm{S}\right.$ e $36^{\circ} 35^{\prime} 42^{\prime \prime}$ 
W), município com período chuvoso entre os meses de fevereiro e abril, já as sementes do lote 2, foram coletadas em Severiano Melo, no mês de janeiro de 2008, a 147

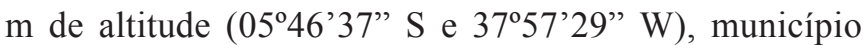
com período chuvoso entre os meses de março e abril; ambos os municípios possuem precipitação pluviométrica anual inferior a $800 \mathrm{~mm}$, característica da região de semiárido. As sementes de cada lote foram obtidas de 10 árvores matrizes e após a colheita foram beneficiadas manualmente, acondicionadas em sacos de plástico e armazenadas em câmara climatizada $\left(18\right.$ a $20{ }^{\circ} \mathrm{C}$ e $50 \%$ UR).

Em laboratório as sementes foram submetidas às seguintes avaliações: a) teor de água: determinado conforme Brasil (1992), utilizando-se duas subamostras de 20 sementes, colocadas em cápsulas de alumínio em estufa a $105{ }^{\circ} \mathrm{C} \pm 3{ }^{\circ} \mathrm{C}$ por 24 horas, sendo os resultados expressos em porcentagem; b) dimensões (comprimento, largura e espessura) das sementes: obtidas por meio de paquímetro digital utilizando-se 100 sementes por lote, sendo expressas em $\mathrm{cm} \cdot$ sementes $^{-1}$; c) peso de mil sementes: realizado com oito subamostras de 100 sementes provenientes da porção semente pura, sendo os resultados expressos em gramas (Brasil, 1992); d) peso hectolítrico: análise realizada em duas repetições retiradas da amostra média, de acordo com Brasil (1992), sendo o resultado expresso em $\mathrm{kg} \cdot \mathrm{hL}^{-1}$; e) teste de germinação: inicialmente realizou-se a assepsia das sementes com solução de hipoclorito de sódio $2 \%$ por 10 minutos; as sementes foram depois lavadas com água destilada e colocadas para secar naturalmente. Em seguida, foram escarificadas na extremidade oposta à micrópila com lixa d'água $\mathrm{n}^{\circ} 80$, para superar a dormência tegumentar (Silva, 2008). Para cada lote foram utilizadas quatro repetições de 25 sementes, distribuídas em duas folhas de papel germitest, previamente umedecidas com quantidade de água equivalente a 2,5 vezes a massa do papel não hidratada e colocada em germinador a $25{ }^{\circ} \mathrm{C}$, sob luz constante. Foram realizadas duas contagens, aos cinco e aos 15 dias após a semeadura (Brasil, 1992; Silva, 2008); f) primeira contagem de germinação: realizada em conjunto com o teste de germinação, sendo o resultado expresso pela porcentagem das plântulas normais avaliadas no $5^{\circ}$ dia após o início do teste; g) envelhecimento acelerado: o teste foi conduzido com sementes escarificadas. Foram usadas caixas de plástico tipo gerbox $(11 \times 11 \times 3 \mathrm{~cm})$, que contém suportes para apoio de uma tela metálica isolando as sementes do contato com a água, sendo as sementes distribuídas em camada simples (Marcos Filho, 1999). Para o controle da umidade relativa no interior do gerbox foram colocados $40 \mathrm{~mL}$ de água destilada e, logo após, as caixas foram tampadas e acondicionadas em câmara à temperatura de $42{ }^{\circ} \mathrm{C}$ por 48 horas. Decorrido esse período, quatro repetições de 25 sementes, para cada lote, foram colocadas em câmara de germinação B.O.D, sob luz contínua, utilizando-se a temperatura constante de $25{ }^{\circ} \mathrm{C}$. Após esse período, efetuou-se a avaliação da germinação, conforme procedimento descrito para o teste de germinação. Foi determinando o teor de água das sementes antes e após o teste de envelhecimento acelerado, visando avaliação da uniformidade dos procedimentos adotados; h) tetrazólio: foram utilizadas quatro repetições de 25 sementes escarificadas para permitir melhor absorção da solução de tetrazólio, submetidas a 48 horas de embebição entre papel toalha a $25{ }^{\circ} \mathrm{C}$, com posterior retirada manual do tegumento. As sementes foram então submersas em solução de tetrazólio a $0,075 \%$ por três horas. Durante o período de coloração as amostras foram mantidas a $35^{\circ} \mathrm{C}$, no escuro. Após este período as sementes foram avaliadas individualmente, seccionando-se longitudinalmente através do centro do eixo embrionário com auxílio de bisturi. As estruturas e sua coloração foram observadas com auxílio de uma lupa estereoscópica. Para a caracterização dos níveis de viabilidade foi elaborada representação de sementes viáveis e não viáveis, observando-se a presença e a localização do dano, além das condições físicas das estruturas embrionárias. A diferenciação de cores dos tecidos foi observada de acordo com os critérios estabelecidos para o teste de tetrazólio (França Neto et al., 1999): vermelho brilhante ou rosa (tecido vivo e vigoroso), vermelho carmim forte (tecido em deterioração) e branco leitoso ou amarelado (tecido morto).

Em casa de vegetação a qualidade das plântulas foi avaliada partindo-se da semeadura, em caixas de plástico contendo vermiculita umedecida com água destilada, onde foram colocadas quatro repetições de 25 sementes escarificadas, por lote. Foram realizadas as seguintes avaliações: a) emergência de plântulas: realizou-se a contagem do número de plântulas emergidas aos cinco dias, estendendo-se até 15 dias após a semeadura. Consideraramse como critério de avaliação as plântulas que apresentavam os cotilédones acima do solo, com os resultados expressos em porcentagem (Silva, 2008); b) índice de velocidade de emergência (IVE): foram realizadas, no mesmo horário, contagens diárias das plântulas normais e emersas durante 15 dias. O índice foi calculado conforme a 
fórmula proposta por Maguire (1962), a seguir: IVE= $(\mathbf{G 1} / \mathbf{N 1})+(\mathbf{G} 2 / \mathbf{N} 2)+\ldots+(\mathbf{G n} / \mathbf{N n})$, onde, $\mathbf{I V E}=$ índice de velocidade de emergência; $\mathbf{G}=$ número de plântulas normais computadas nas contagens; $\mathbf{N}=$ número de dias da semeadura à $1^{\mathrm{a}}, 2^{\mathrm{a}}, .$. , n-ésima avaliação; c) comprimento médio de plântulas: realizado conjuntamente com o teste de emergência, sendo as plântulas coletadas, mensuradas com régua e o resultado expresso em $\mathrm{cm}$.plântula ${ }^{-1}$; d) massa da matéria verde e seca de plântulas: após 15 dias da semeadura, as plântulas foram cortadas rente ao solo, acondicionadas em sacos de papel (kraft), divididas por repetições/lotes determinando-se a massa da matéria verde, sendo logo após colocadas em estufa a $65 \pm 3{ }^{\circ} \mathrm{C}$ por 48 horas e posteriormente determinando-se, em balança $(0,001 \mathrm{~g})$, a massa seca de plântulas. $\mathrm{O}$ valor obtido em cada repetição/lote foi dividido pelo número de plântulas utilizadas e os resultados expressos em mg.plântula ${ }^{-1}$ (Nakagawa, 1999).

A comparação entre as médias dos caracteres para os dois lotes foi realizada utilizando-se os intervalos de confiança obtidos pelo teste t, com $95 \%$ de probabilidade.

\section{RESULTADOS E DISCUSSÃO}

O teor de água das sementes dos dois lotes foi similar (Tabela 1). De acordo com Marcos Filho (2005), a variação no teor de água das sementes dos diferentes lotes não deve ser superior a $2 \%$, pois as sementes mais úmidas são mais sensíveis às condições dos testes e, portanto, sujeitas a deterioração mais intensa. Verificou-se baixa variação nos valores médios do peso hectolítrico e peso de mil sementes entre os lotes avaliados. Também, não houve grande variação dos valores médios de comprimento, largura e espessura das sementes dos dois lotes (Tabela 1), provavelmente porque as regiões onde foram coletadas as sementes possuem características semelhantes. Em pesquisas realizadas com mulungu, em brejo de altitude e caatinga, Silva Júnior (2005) constatou variação nas dimensões das sementes, quando as coletas ocorreram em locais distintos.

TABELA 1. Características físicas de sementes de mulungu (Erythrina velutina Willd.) avaliadas pelo teor de água (TA), peso de mil sementes (PMS), peso hectolítrico (PH), comprimento (C), largura (L) e espessura (E).

\begin{tabular}{clccccc}
\hline Lotes & TA $(\%)$ & PMS $(\mathrm{g})$ & PH $\left(\mathrm{kg} \cdot \mathrm{hL}^{-1}\right)$ & $\mathrm{C}\left(\mathrm{cm} \cdot \mathrm{semente}^{-1}\right)$ & $\mathrm{L}(\mathrm{cm})$ & $\mathrm{E}(\mathrm{cm})$ \\
\hline 1 & 7,4 & 42,17 & 56,40 & 1,30 & 0,80 & 0,78 \\
2 & 7,6 & 46,76 & 57,00 & 1,34 & 0,86 & 0,81 \\
\hline
\end{tabular}

Com exceção dos resultados obtidos no teste de tetrazólio, nos demais testes não foram verificadas diferenças entre os dois lotes de sementes de mulungu, ocorrendo sobreposição dos intervalos de confiança obtidos a partir do teste $\mathrm{t}$ com $95 \%$ de probabilidade (Tabela 2). A porcentagem de germinação das sementes foi alta, $99 \%$ e $97 \%$ para os lotes 1 e 2 respectivamente, indicando elevado poder germinativo das sementes dos dois lotes, o que é fator preponderante na comparação pois os testes de vigor podem detectar diferenças não observadas no teste de germinação (Marcos Filho, 1999). O potencial fisiológico das sementes é rotineiramente avaliado pelo teste de germinação, conduzido sob condições altamente favoráveis de temperatura, umidade e substrato, viabilizando assim, o máximo potencial para germinação, não refletindo o comportamento das espécies no campo e não detectando, portanto, estágios avançados de deterioração (Larré et al., 2009).
Não houve diferença entre os lotes para primeira contagem de germinação e índice de velocidade de emergência (Tabela 2). $\mathrm{O}$ teste de primeira contagem de germinação, muitas vezes, expressa melhor as diferenças de velocidade de germinação, porém Valentini e PinaRodrigues (1995) ressaltaram que esse teste possui eficiência reduzida quanto à detecção de pequenas diferenças de vigor.

Para o teste de envelhecimento acelerado também não foi verificada diferença entre lotes (Tabela 2). Observou-se grande elevação no teor de água das sementes para os dois lotes envelhecidos a $42^{\circ} \mathrm{C}$, os quais apresentavam valor inicial médio de $7,4 \%$ para o lote 1 e de $7,6 \%$ para o lote 2 , atingindo o máximo de $49,8 \%$ e 46,5\%, respectivamente para os lotes 1 e 2, após $48 \mathrm{~h}$ de permanência na câmara de envelhecimento acelerado (Tabela 2). Esse elevado teor de água após o período de envelhecimento provavelmente se deve à escarificação 
prévia a qual as sementes foram submetidas. Em trabalho realizado com sementes de Macrotyloma axillare (E. Mey.)
Verdc. cv. Java, Paiva et al. (2008), encontraram $46,8 \%$ de teor de água após $48 \mathrm{~h}$ de envelhecimento.

TABELA 2. Médias e intervalos de confiança com $95 \%$ de probabilidade para germinação (G), primeira contagem da germinação (PCG), emergência de plântula (EP), índice de velocidade de emergência (IVE), teor de água após o envelhecimento (TAE), envelhecimento acelerado (EA) e teste de tetrazólio (TZ), em dois lotes de sementes de mulungu (Erythrina velutina Willd.).

\begin{tabular}{cccccccc}
\hline Lotes & G $(\%)$ & PCG $(\%)$ & EP(\%) & IVE $(\%)$ & TAE $(\%)$ & EA(\%) & TZ $(\%)$ \\
\hline \multirow{2}{*}{1} & 99,0 & 32,0 & 77,0 & 4,2 & 49,8 & 89,0 & 49,0 \\
& $(95,8 ; 102,2)$ & $(14,8 ; 49,2)$ & $(50,8 ; 103,2)$ & $(2,5 ; 6,0)$ & - & $(82,9 ; 95,1)$ & $(47,2 ; 50,8)$ \\
\hline \multirow{2}{*}{2} & 97,0 & 37,0 & 75,0 & 4,3 & 46,5 & 82,0 & 42,0 \\
& $(93,8 ; 100,2)$ & $(27,5 ; 46,6)$ & $(61,9 ; 88,1)$ & $(3,3 ; 5,2)$ & - & $(73,8 ; 90,2)$ & $(39,4 ; 44,6)$ \\
\hline
\end{tabular}

A diferença entre os teores de água dos dois lotes após os períodos de envelhecimento foi de 3,3\%. Para Marcos Filho (1999), um dos principais indicadores da uniformidade das condições de envelhecimento acelerado é o teor de água das sementes ao final do teste, pois variações de 3 a 4\% entre amostras são consideradas toleráveis. Cabe salientar que esse teste necessita de adequação para ser utilizado nessa espécie, assim como os testes baseados na taxa de crescimento de plântulas, por estarem sujeitos às variações ambientais.

O teste de tetrazólio foi o único que detectou diferença entre as médias estimadas para os dois lotes, indicada pela não sobreposição dos intervalos de confiança obtidos com 95\% de probabilidade pelo teste $\mathrm{t}$ (Tabela 2). Os resultados dos demais testes foram coerentes com os de emergência de plântulas, conduzido em condições de casa de vegetação. Tal fato se deve possivelmente à imprecisão do teste de tetrazólio quando aplicado a sementes de mulungu, uma vez que não há relatos na literatura sobre sua utilização nesta espécie.

Estudos que se referem a limitações do teste de terazólio na avaliação da viabilidade de sementes já foram publicados na literatura. As diferenças de cor observadas nas sementes após a coloração na solução de tetrazólio são as principais características que devem ser consideradas na interpretação dos resultados do teste. A intensidade de coloração das sementes no teste de tetrazólio é variável entre as espécies (Oliveira et al., 2009). Essas diferenças podem acarretar problemas de interpretação durante a avaliação das sementes. Por essa razão é interessante utilizar-se de métodos padronizados, correlacionando-se as cores observadas nas sementes com uma referência não subjetiva.

Para as espécies florestais brasileiras o teste de tetrazólio é utilizado de forma restrita, embora apresente potencial para ser empregado rotineiramente, uma vez que parte dessas espécies necessita de um período longo para as sementes germinarem (Pinto et al., 2008). Algumas pesquisas foram realizadas com o objetivo de padronizar esse teste para avaliação da viabilidade de sementes de espécies florestais brasileiras, como as desenvolvidas para as sementes de Peltophorum dubium (Sprengel) Taubert (Oliveira et al., 2005), Schizolobium parahyba (Vell.) Blake (Ferreira et al., 2007) e Poecilanthe parviflora Benth (Pinto et al., 2008).

Não foram detectadas diferenças entre os lotes para altura de plântulas, diâmetro do colo, massa da matéria verde e seca de plântulas (Tabela 3), a exemplo do que foi verificado nos testes de germinação e vigor.

TABELA 3. Médias e intervalos de confiança com $95 \%$ de probabilidade para altura $(\mathrm{A})$, diâmetro do colo (DC), massa da matéria verde (MMV) e massa da matéria seca (MMS) por plântulas de dois lotes de sementes de mulungu (Erythrina velutina Willd.).

\begin{tabular}{ccccc}
\hline Lotes & A (cm) & DC $(\mathrm{cm})$ & MMV $(\mathrm{g})$ & MMS (g) \\
\hline \multirow{2}{*}{1} & 29,6 & 36,3 & 56,0 & 4,2 \\
& $(27,5 ; 31,8)$ & $(30,2 ; 42,3)$ & $(36,5 ; 75,6)$ & $(2,6 ; 5,7)$ \\
\hline \multirow{2}{*}{2} & 29,8 & 34,8 & 54,7 & 4,6 \\
& $(27,1 ; 32,4)$ & $(32,8 ; 36,8)$ & $(42,7 ; 66,7)$ & $(4,1 ; 5,1)$ \\
\hline
\end{tabular}




\section{CONCLUSÕES}

Os testes de germinação, primeira contagem, índice de velocidade de emergência e envelhecimento acelerado são coerentes com o teste de emergência de plântulas em casa de vegetação e com a caracterização biométrica das sementes e indicam homogeneidade entre os dois lotes de sementes de mulungu.

Há necessidade de estudos mais detalhados sobre a aplicabilidade do teste de tetrazólio em sementes de mulungu.

\section{AGRADECIMENTOS}

Os autores agradecem às instituições CNPq e CAPES pelas concessões das bolsas de pesquisa; aos Engenheiros Agrônomos Dr. Dyeme Antonio Vieira Bento, melhorista da Nunhems pelas valiosas sugestões, correções e contribuição na análise estatística; ao Dr. Glauber Henrique, Prof. da UFERSA-RN, pelo auxílio na análise estatística.

\section{REFERÊNCIAS}

ASSOCIATION OF OFFICIAL SEED ANALYSTS. Seed vigour testing handbook. East Lasing, 1983. 88p. (To the Handbook on Seed Testing. Contribution, 32).

BARBOSA, A.P.; SAMPAIO, P.T.B. CAMPOS, M.A.A.; VARELA, V.P.; GONÇALVES, C.Q. B.; IIDA, S. Tecnologia alternativa para a quebra de dormência das sementes de pau-de-balsa (Ochroma lagopus Sw., Bombacaceae). Acta Amazônica, v.34, n.1, p.107-110, 2004.

BRASIL. Ministério da Agricultura e Reforma Agrária. Secretaria Nacional de Defesa Agropecuária. Departamento Nacional de Defesa Vegetal. Coordenação de Laboratório Vegetal. Regras para análise de sementes. Brasília, DF, 1992. 365p.

FERREIRA, R.A.; OLIVEIRA, L.M. DE; TONETT, O.A.O.; DAVIDE, A.C. Comparação da viabilidade de sementes de Schizolobium parahyba (Vell.) BlakeLeguminosae Caesalpinioideae, pelos testes de germinação e tetrazólio. Revista Brasileira de Sementes, v.29, n.3, p.83-89, 2007.

FRANÇA NETO, J. B.; KRZYZANOWSKI, F.C.; COSTA, N.P. Metodologia do teste de tetrazólio em sementes de soja. In: KRZYZANOWSKI, F.C.; VIEIRA, R.D.; FRANÇA NETO, J.B. (Ed.). Vigor de sementes: conceitos e testes. Londrina: ABRATES. 1999. p.8.5-1-8.5-28.
GONÇALVES, E.P.; PAULA, R.C.; DEMATTÊ, M.E.S.P.; SILVA, M.A.D. Potencial fisiológico de sementes de mutambo (Guazuma ulmifolia Lam.) em diferentes procedências. Revista Caatinga, v.22, n.2, p.218-222, 2009.

LARRÉ, C.F.; MORAES, D.M. DE; LOPES, N.F. Potencial fisiológico de dois lotes de sementes de arroz tratadas com 24-epibrassinolídeo. Revista Brasileira de Sementes, v.31, n.4, p.27-35, 2009.

LORENZI, H. Árvores brasileiras: manual de identificação e cultivo de plantas arbóreas nativas do Brasil. 2. ed. v.1. Nova Odessa: Instituto Plantarum. 2002. 368p.

MAGUIRE, J.D. Speed of germination aid in selection and evaluation for seedling emergence and vigor. Crop Science, v.2, n.2, p.176-77, 1962.

MARCOS FILHO, J. Teste de envelhecimento acelerado. In: KRZYZANOWSKI, F.C.; VIEIRA, R.D.; FRANÇA NETO, J.B (Ed.). Vigor de sementes: conceitos e testes. Londrina: ABRATES, 1999. cap.3, p.1-24.

MARCOS FILHO, J. Fisiologia de sementes de plantas cultivadas. Piracicaba: FEALQ, 2005, p.477.

MARTINS, L.; LAGO, A.A. DO; SALES, W.R.M. Conservação de sementes de ipê-amarelo (Tabebuia chrysotricha (Mart. ex DC.) Standl.) em função do teor de água das sementes e da temperatura do armazenamento. Revista Brasileira de Sementes, v.31, n.2, p.86-95, 2009.

MATHEUS, M.T.; LOPES, J.C. Temperaturas cardinais para a germinação de Erythrina variegata L. Revista Brasileira de Sementes, v.31, n.3, p.115-122, 2009.

MELO, R.R.; CUNHA, M.C.L. Crescimento inicial de mudas de mulungu (Erythrina velutina Wild.) sob diferentes níveis de luminosidade. Ambiência Guarapuava, v.4, n.1, p.67-77, 2008.

MENDONÇA, E.A.F. DE; AZEVEDO, S.C. DE; GUIMARÃES, S.C.; ALBUQUERQUE, M.C.F. Testes de vigor em sementes de algodoeiro herbáceo. Revista Brasileira de Sementes, v. 30, n.3, p.1-9, 2008.

NAKAGAWA, J. Testes de vigor baseados no desempenho de plântulas. In: KRZYZANOWSKI, F.C.; VIEIRA, R.D.; FRANÇA NETO, J.B. (Ed.). Vigor de sementes: conceitos e testes. Londrina: ABRATES, 1999. cap.2, p.1-24.

NUNES, S.C.P.; NUNES, U.R.; FONSECA, P.G.; GRAZZIOTTI, P.H.; PEGO, R.G.; MARRA, L.M. Época, local de colheita e armazenamento na qualidade fisiológica da semente de sempre-viva (Syngonanthus elegans (Bong.) Ruhland-Eriocaulaceae). Revista Brasileira de Sementes, 
v.30, n.1, p.32-39, 2008.

OLIVEIRA, C.M.G.; MARTINS, C.C.; NAKAGAWA, J. Concentração da solução de tetrazólio e período de coloração do teste para sementes de mamoneira. Revista Brasileira de Sementes, v.31, n.3, p.38-47, 2009.

OLIVEIRA, L.M.; CARVALHO, M.L.M.; DAVIDE, A.C. Teste de tetrazólio para avaliação da qualidade de sementes de Peltophorum dubium (Sprengel) Taubert - Leguminosae Caesalpinioideae. Cerne, v.11, n.2, p.159-166, 2005.

PAIVA, A.S., RODRIGUES T.J.D., CANCIAN A.J., LOPES M.M., FERNANDES, A.C. Qualidade de sementes de macrotiloma (Macrotyloma axillare) Cv. Java. Revista Brasileira de Sementes, v.30, n.2, p.130-136, 2008.

PINTO, T.L.F.; MARCOS FILHO, J.; FORTI, V.A.; CARVALHO, C. DE; GOMES JÚNIOR, F.G. Avaliação da viabilidade de sementes de pinhão manso pelos testes de tetrazólio e de raios X. Revista Brasileira de Sementes, v.31, n.2, p.195-201, 2009.

PINTO, T.L.F.; BRANCALION, P.H.S.; NOVEMBRE, A.D.L.C.; CÍCERO, S.M. Avaliação da viabilidade de sementes de coração-de-negro (Poecilanthe parviflora Benth.-Fabaceae-Faboideae) pelo teste de tetrazólio. Revista Brasileira de Sementes, v.30, n.1, p.208-214, 2008 .
SILVA JÚNIOR, V.T. Biometria, germinação e crescimento inicial de Erythrina velutina Willd (Leguiminosae-Papilionoideae) ocorrente em caatinga e brejo de altitude (PE). 2005. 70f. Dissertação (Mestrado em Biologia Vegetal) - Universidade Federal de Pernambuco, Recife, 2005.

SILVA, K.B. Tecnologia de sementes de Erythrina velutina Willd. 2008. 138f. Dissertação (Mestrado em Agronomia) - Universidade Federal da Paraíba, Areia, 2008.

SILVA, B.M.S.; CARVALHO, N.M. Efeitos do estresse hídrico sobre o desempenho germinativo da semente de faveira (Clitoria fairchildiana R. A. Howard. - Fabaceae) de diferentes tamanhos. Revista Brasileira de Sementes, v. 30, n.1, p.55-65, 2008.

TEKRONY, D.M. Accelerated aging. In: VAN DE VENTER, H.A. (Ed.). Seed vigour testing seminar. Copenhagen: The International Seed Testing Association. p.53-72, 1995.

VALENTINI, S.R.T.; PIÑA-RODRIGUES, F.C. Aplicação do teste de vigor em sementes. São Paulo: [s.n.], 1995. p.75-84 (IF Série Registro, 14). 